\title{
Universal access to affordable health care
}

\author{
Gilbert Berdine MD
}

\begin{abstract}
Never let a crisis go to waste. The New England Journal of Medicine (NEJM) recently framed another request for single payer health care in the context of the COVID-19 pandemic. "The COVID-19 pandemic has brought into sharp focus the need for health care reforms that promote universal access to affordable care." We already have universal access to affordable health care. ${ }^{2}$ Take bandages for example. Bandages are used to keep minor abrasions and lacerations from becoming infected. Bandages are readily available at affordable prices due to the miracle of the free market. Nobody needs insurance or a government subsidy to pay for a bandage.
\end{abstract}

People who request universal access to affordable health care, including the NEJM, really want universal access to UNAFFORDABLE health care. The word 'unaffordable' means you cannot afford it, so it becomes self-evident why universal access is impossible. So, people, like those at NEJM, utilize George Orwell's concept of Newspeak and replace the word 'unaffordable' with its opposite word 'affordable.'

Confucius said, "The beginning of wisdom is to call things by their proper name." Rather than following the advice of Confucius and calling unaffordable health care by its proper name, advocates for universal health care put an exclamation point on their request by claiming a right to all health care whether it is affordable or not. One can even find claims to a health care right alongside convoluted schemes to "fairly" ration health care even though a ration is incompatible with a right to something. Reasonable people can disagree on the morally best way to ration scarce health care, but we will not arrive at a consensus by incorrectly claiming a right to unaffordable health care.

Corresponding author: Gilbert Berdine

Contact Information: Gilbert.Berdine@ttuhsc.edu DOI: 10.12746/swrccc.v8i35.723
The NEJM request for universal access to unaffordable health care starts with a convoluted scheme to continue insurance policies provided by employers to workers recently unemployed by government mandated lockdowns. The NEJM plan is no longer health insurance. ${ }^{3}$ Health insurance is pooled risk of uncertain future events. People at risk for future catastrophic events pre-pay into a pool so that when such an event occurs, there are funds available to cover the catastrophe. Insurance works only for insurable events. One cannot insure against events that have already occurred. The proper term for schemes where people buy "insurance" after the fact would be something like an option to buy health care at a discount to its cost. The NEJM eventually gets around to paying for its scheme with federal money to reimburse providers for treating the uninsured at Medicare or Medicaid rates.

Since the free market can, without any effort by government, supply universal access to affordable health care, we should endeavor to explain why some health care is unaffordable, and, once explained, endeavor to make the previously unaffordable item into something affordable in the future. Unaffordable health care can be divided into two categories: health care that should be affordable but is unaffordable due to government meddling and health care that is unaffordable due to the very high cost necessary to produce it.

Consider two objects of similar complexity, size, and material costs: a toaster and a CPAP machine. Toasters are generally available to everyone for less than $\$ 20$ which represents a few hours of labor at minimum wage. Nobody demands that toasters be covered by insurance. A continuous positive airway pressure (CPAP) machine is the standard therapy for obstructive sleep apnea (OSA). Why does a CPAP machine, which is similar in complexity, size, and material costs to a toaster, cost several hundreds of dollars or more? The key difference is the cost of obtaining government permission to sell CPAP machines compared with toasters. 
Some government regulations, always under the guise of consumer safety, make some health care, like CPAP machines, unaffordable. In some cases, such as patent monopoly or license monopoly, the government makes competition illegal. The absence of competition makes the price higher than it would be with robust competition. In some cases, the requirements to satisfy government agencies that a product is safe are very expensive and/or complicated limiting potential suppliers to very large enterprises with armies of lawyers and lobbyists. The regulatory process is a barrier against competition by small enterprises that are the source of much innovation. Safety standards are frequently established by former employees of these large enterprises who craft the standards to limit competition rather than protect the public. This process is called regulatory capture by the regulated.

Many pharmaceuticals are affordable and universal access is provided by the free market. Acetaminophen is an example. Nobody requires insurance to purchase acetaminophen. The cost of acetaminophen is kept affordable by robust competition. Any attempt to raise the price to outrageous levels would lead to new suppliers eager to capture market share and profits by offering supply at affordable prices.

Some pharmaceuticals are unaffordable. ${ }^{4}$ The primary reason is monopoly privilege granted by government. Government makes it illegal for competitors to sell the same chemicals at affordable prices, so the monopolist can get away with charging outrageous prices. Even with monopoly privilege, pricing in an otherwise free market would be less than what is seen in the United States. A corporation motivated only by greed would not charge the maximum price that anyone could afford as this price would not maximize profit. Maximum profits would require lower prices that maximized the product of number of purchases times the price per purchase. The lower the price, the greater the number of people willing to purchase. A popular strategy for pharmaceutical companies is to obtain monopoly privilege, convince a government entity such as Medicare to subsidize purchase of the drug, and then maximize the number of indications for use of the drug.

Some things are truly unaffordable. The U.S. first put men on the moon over 50 years ago. The reason we do not have commercial service to and from the moon is that such an endeavor is enormously expensive compared with benefits and, therefore, unprofitable. It is unclear that there is anything on the moon sufficiently valuable to a large enough number of consumers to make travel to and from the moon profitable and, therefore, affordable.

Some types of health care are unaffordable because the cost is too high, wealth is limited, and given individual budgets, individuals have higher priorities than health care such as food, shelter, and clothing. One survivor of COVID-19, Michael Flor, received health care with a price tag of $\$ 1.1$ million. ${ }^{5}$ Obviously, Mr. Flor thought the money was well spent. Based on a photo in the article, so did the health care providers. However, Mr. Flor was perceptive enough to admit that everyone else might not agree. Insurance can handle outlier cases, but we cannot possibly spend $\$ 1.1$ million dollars on every person every year. Our average expense cannot exceed our average income.

Some things are affordable only to the rich. Wealthy individuals can afford things that are unaffordable to people with average income. Some things are affordable to those with average income but unaffordable to the poor. The above statements are equally true for societies as for individuals. Charity can make some aspects of health care available to the poor, but charity cannot make things that are unaffordable to average people affordable to an entire society. ${ }^{6}$ Attempts to provide unaffordable health care to everyone are not only futile, but they are also counterproductive.

Charity is a form of current consumption. Wealth spent on charity is unavailable for other current consumption or for capital investment. The purpose of capital investment is a future increase in productive capacity. Any shift of capital investment to current consumption means future profit will be less than it otherwise would be, reducing the potential for future charity. Some current consumption is necessary for maintenance of current productive capacity. Some current consumption on leisure is necessary for maintenance of our mental health. When does leisure exceed what is necessary for maintenance and become gluttony or decadence? What is the proper balance between current consumption for charity and investment in future 
productive capacity? These are subjective questions without objectively correct answers. Private charity allows society to answer these questions according to the current preferences of individuals who have wealth available for charity. Public charity empowers bureaucrats to endanger future productive capacity with unlimited claims to wealth for current consumption.

The free market already provides universal access to affordable health care. It is not possible to provide universal access to unaffordable health care. We should strive to transform what is currently unaffordable into something affordable in the future. In some cases, all that is necessary is for government to get out of the way. In other cases, we should stop acting like spoiled children and recognize that health care, like everything else, has a limited budget.

Keywords: health care, costs, free market, insurance

Article citation: Berdine G. Universal access to affordable health care. The Southwest Respiratory and Critical Care Chronicles 2020;8(35):65-67

From: Department of Internal Medicine, Texas Tech University Health Sciences Center, Lubbock, Texas

Submitted: $6 / 29 / 2020$

Accepted: 7/4/2020

Conflicts of interest: none

This work is licensed under a Creative Commons

Attribution-ShareAlike 4.0 International License.

\section{REFERENCES}

1. King JS. Covid-19 and the need for health care reform. N Engl J Med 2020;382:e104.

2. Berdine G. Affordable health care: what it means and how do we fix our current unaffordable system. The Southwest Respiratory and Critical Care Chronicles 2017;5(21):36-41.

3. Berdine G. Sustainable health insurance. The Southwest Respiratory and Critical Care Chronicles 2018;6(25):63-68.

4. Berdine, G. Why some pharmaceuticals are so expensive. Mises Institute. https://mises.org/wire/why-some-pharmaceuticals-areso-expensive. Accessed 6/29/2020.

5. Westneat $D$. Coronavirus survival comes with a $\$ 1.1$ million, 181-page price tag. The Seattle Times. https://www. seattletimes.com/seattle-news/inspiring-story-of-seattle-manscoronavirus-survival-comes-with-a-1-1-million-dollar-hospitalbill/. Accessed 6/29/2020.

6. Berdine G. Charity vs. government health care. The Southwest Respiratory and Critical Care Chronicles 2018;6(26):51-57. 